\title{
A Future for Crocodiles
}

\author{
H. Robert Bustard
}

Papua and New Guinea have the makings of a sizeable skin industry based on the two native crocodiles. But the industry today is in danger of collapse as a result of overhunting in the accessible crocodile areas. The best hope for conserving the crocodile is to build up the numbers to enable the industry to thrive on a sustained yield basis, so that the people will accept crocodile conservation as sensible, practicable and profitable. Dr. Bustard has made an extensive survey and study of the problem in the Territory, and here describes the situation and the recommendations he has made to the Government.

Crocodiles do not readily arouse public sympathy, and the best argument for conserving them is their economic value. Governments are more likely to enact effective legislation to maintain substantial breeding stocks once it is demonstrated that their skins are a valuable resource, and that crocodiles, properly managed, can provide an annual crop as in modern farming. As it is, the indiscriminate shooting which is now going on all over the world will, if it is not checked, destroy the resource completely.

In 1967, at the invitation of the Australian Minister of External Territories, I made a survey in the Territory of Papua-New Guinea of the status and composition of crocodile populations, examined the operation of the crocodile skin industry in order to make recommendations for effective legislation, and drew up a management plan designed to produce a maximum quantity of high quality leather on a sustainable yield basis.

Papua-New Guinea consists of a central mountain chain, the 'Highlands', and extensive swamplands that provide vast areas of ideal crocodile habitat but are otherwise of little economic value. The two species of crocodile there are the saltwater crocodile, Crocodylus porosus, which occurs throughout SE Asia as far south as northern Australia, and the New Guinea endemic species C. novaeguineae, called the freshwater crocodile (although the saltwater crocodile often spends its entire life in fresh water many hundreds of miles from the sea), whose skin is particularly prized, being valued at present at $28 \mathrm{~s}$ per belly inch. The demand for crocodile skins is certain to grow, and, with the present over-exploitation of the world's crocodiles, to out-strip supply. Any country which can create a managed industry will reap a rich reward.

For some years there has been considerable dissatisfaction with the operating methods of the crocodile skin industry in Papua-New Guinea, at least in the Western District of Papua, and in March 1966 Mr. Robert Tabua, M.H.A., announced his intention of presenting a private member's bill to regulate the industry. In December I was asked by the Administration for advice in drafting what became the 
Crocodile Trade (Protection) Ordinance of 1966. But although this was passed by the House and received the assent early in 1967 , none of its provisions were implemented. The acute problem concerned the future of the industry, which was in danger of collapse due to overhunting. There was little danger of either crocodile species becoming extinct, as is certainly the case in other parts of the world, but vast areas of river and swamplands which were prime crocodile areas were (and are) so over-exploited as to be non-productive to the industry, and, incidentally, useless for other forms of development.

Crocodile shooting for profit has been in operation in the Territory for about twenty years, in the early years almost exclusively by expatriates. Crocodiles were very numerous, large specimens were common, and people admit to having shot many more crocodiles than they could possibly skin. The result was a drastic reduction in numbers, especially in the medium size range (6-1o $\mathrm{ft}$ ) which produces the best quality skin. Skin prices have risen steeply in recent years, so, as the animals became less abundant, shooters turned to smaller crocodiles which provided skins previously unacceptable. This intensified hunting for young crocodiles completely disguised the downward trend of populations; indeed, the export value of skins continued to increase.

On both the Fly and the Sepik there are many areas where crocodiles have been shot out, and are now only to be found in any abundance in the more inaccessible swamps. During our survey an evening's searching at Lake Murray disclosed only one crocodile. On the Fly between the Avu River and d'Albertis the average number of crocodiles seen on each of two nights was four; below d'Albertis none were seen. On the whole of the Sepik, in eight nights hunting, only six crocodiles were sighted. Fortunately one major breeding area for the saltwater crocodile still exists on the Sepik, although it is now threatened.

\section{Mainly Small Crocodiles Caught}

A further result of shooting out the readily accessible crocodiles was the introduction of the native people to the industry. They were given supplies of salt, torches, batteries, etc., and encouraged to find and shoot crocodiles. The result today is that the expatriates are largely skin buyers from the native people who do nearly all the hunting. They thus have an important (and lucrative) role in the industry which should be maintained under management. Today medium-sized crocodiles have largely been shot out even in areas accessible only to native hunters, and small crocodiles make up the bulk of the catch. In many accessible areas the crocodiles have only been saved from complete extermination by the extreme wariness of the large specimens (Io $\mathrm{ft}$ and up) which are the last remaining breeders. But even these are now threatened by means other than shooting.

The hunters shoot or spear at night, using torches. The red reflections from crocodiles' eyes are readily picked up at a distance in the bright light, which dazzles the animal while the hunter approaches to shoot from very close range. There are indications that crocodiles soon become 'light-shy' (Bustard, I968), but it is possible to shoot 
most of a population when they are first sighted. The weight of the stones in the stomach (which act as ballast) causes the animal to sink immediately when shot, so close approach is essential. Harpooning, the original and effective native way of catching even substantial-sized crocodiles, is still widespread. Netting also takes place but is nowhere common, presumably due to the cost of nets. The large wary crocodiles can only readily be caught on hooks, a method that is completely nondiscriminatory for size, and is now destroying the last remaining breeders in some areas. In the Fly River hooks are little used, but they are extensively used in the Sepik.

The morning following shooting the catch is skinned-a skilled operation, for a grade I skin can easily be spoilt and its value greatly reduced by small cuts resulting from careless knife-work. Skinning must be followed by scraping the inside of the skin to remove all adherent flesh. The skin is then thoroughly salted, rolled up and stored until it can be sold to a buyer for one of the large overseas tanneries.

\section{Result of Co-operation}

On the Fly River, in Papua, the skin buyers have always been in close touch with the native people and have taught them how to prepare skins; the result is a high proportion of top quality skins. But on the Sepik River in New Guinea there are always high proportions of lower grade and even unsaleable skins. Poor skinning, total lack of scraping, and inadequate salting were all much in evidence among skins in Angoram. The smaller sizes and much lower quality of the Sepik skins can only be explained by the lack of close co-operation between buyer and hunter/skinner, resulting from the intrusion there of expatriate middlemen interested not in quality but only in profit.

Very little is known about crocodile biology and it will be several years before a working knowledge of the New Guinea species is available. Priority should be given to an intensive study of reproduction, which is required for future population management, for hatchery programmes, and to demonstrate the value of protecting the larger breeding stock.

The Nile crocodile has been shown, on the basis of over 500 dissections, to reach sexual maturity at between 9 and II feet (Cott, I96I). The saltwater crocodile of New Guinea is of a smiliar size to the Nile crocodile and probably starts breeding at a similar size. Native people, who had shot female saltwater crocodiles during the breeding season, when asked the size of the smallest female found to contain eggs, independently gave measurements ranging between 8 and Io feet. We examined a female specimen measuring $9 \mathrm{ft} .6 \frac{1}{2}$ in. and this was sexually mature. The New Guinea freshwater crocodile is known to start breeding earlier since it is a smaller species. Females probably start breeding at about 5-6 feet; the largest I examined measured $5 \mathrm{ft}$. 3 in. and was still sexually immature. It is because the saltwater crocodile must grow to this large size before being able to breed that numbers have decreased so severely. However, because the reptiles are long-lived, an upper size limit will protect the breeding stock. 
Moreover, as crocodiles grow they lay much larger egg clutches. For instance at 9 feet (first breeding) the Nile crocodile lays about 35 eggs but at II $\frac{1}{2}$ feet it lays about 85 eggs (Cott, I96I).

There is little danger to humans from crocodiles. Like lions and tigers they usually shun man, but occasionally individuals, after eating a human, become man-eaters, and the few instances of attack have received wide publicity. The Ordinance makes provisions for such specimens to be hunted and shot. Their effect on fisheries may well be beneficial, for crocodiles feed largely on fish that are comparatively worthless (compared with commercially desirable forms like Tilapia), and some of which are themselves at some stage predatory on fish, fry or fish-eggs. Thus crocodile destruction is unlikely to benefit fishery interests, and might well be harmful (Cott, 196I).

At the time of our survey we found that everyone, native and European alike, favoured protective legislation for the industry. We sounded native opinion at length in Angoram and in many villages on the Sepik and Fly Rivers, discussing size limitations, the prohibition of the taking of eggs or undersized crocodiles as food, the prohibition of hooking and netting and the possibility of the people setting up crocodile hatcheries in the villages. In most of them the response was excellent. It should be stressed that many of the Fly and Sepik River people are intimately concerned with crocodiles and possess a unique knowledge of them. Their economic progress is in large measure tied to the crocodile skin trade and they are prepared to co-operate to restore the industry to profitability. All Europeans see the need for size restrictions at least at the lower limit, and some, acting alone or in concert with an overseas buyer, have tried to stop the slaughter of tiny crocodiles (under 8 in. bellies). But all agree that as long as these skins may be legally sold someone will purchase them.

\section{The Possibilities}

The industry can be developed in four ways: by increasing the quantity of skin taken; by taking skins at the most economic and valuable size; by taking precautions to see that the overall quality of the skin is first grade; and by the development of a tannery in the Territory and the limited use of tanned skins within the Territory. The first two can be achieved by size limits: the upper limit will result in a greatly enhanced production of young crocodiles, the lower will ensure that these crocodiles are left to grow to an economic size. The combination of more and larger crocodiles will result in a much larger quantity of skins being taken. Ensuring first grade skins can best be achieved by encouraging close contact between the buyer and native hunter who prepares the skin, and the traditional close contact on the Fly, which results in a high standard of skins, should be extended to the Sepik. This can be brought about by licensing.

\section{Recommendations}

Four major recommendations followed from the survey:

r. The ownership problem: any rationalisation of the crocodile skin 


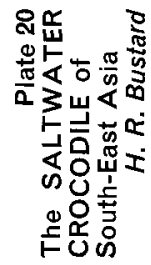

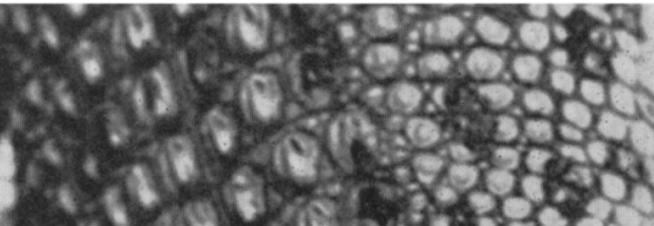
91000 m

$\checkmark$.

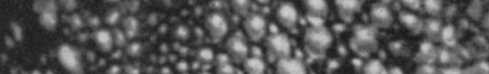

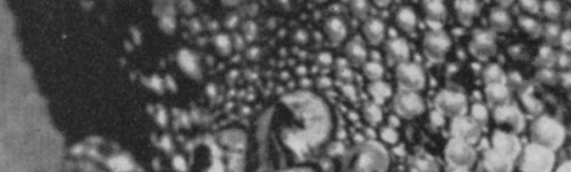

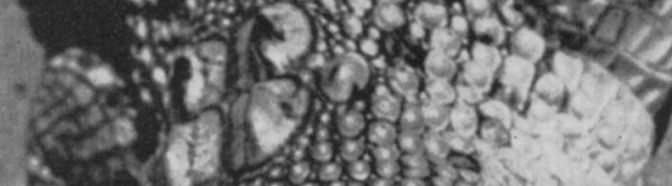

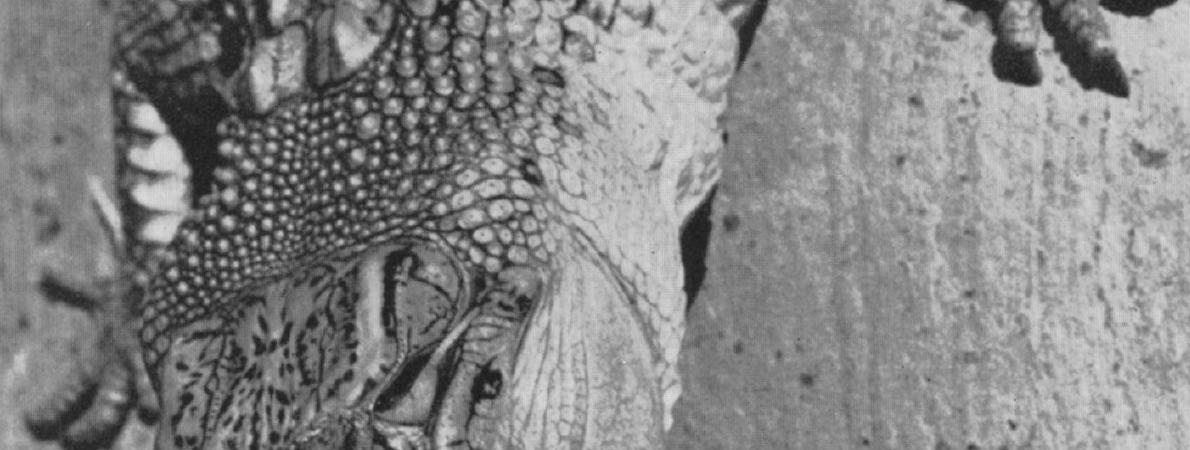



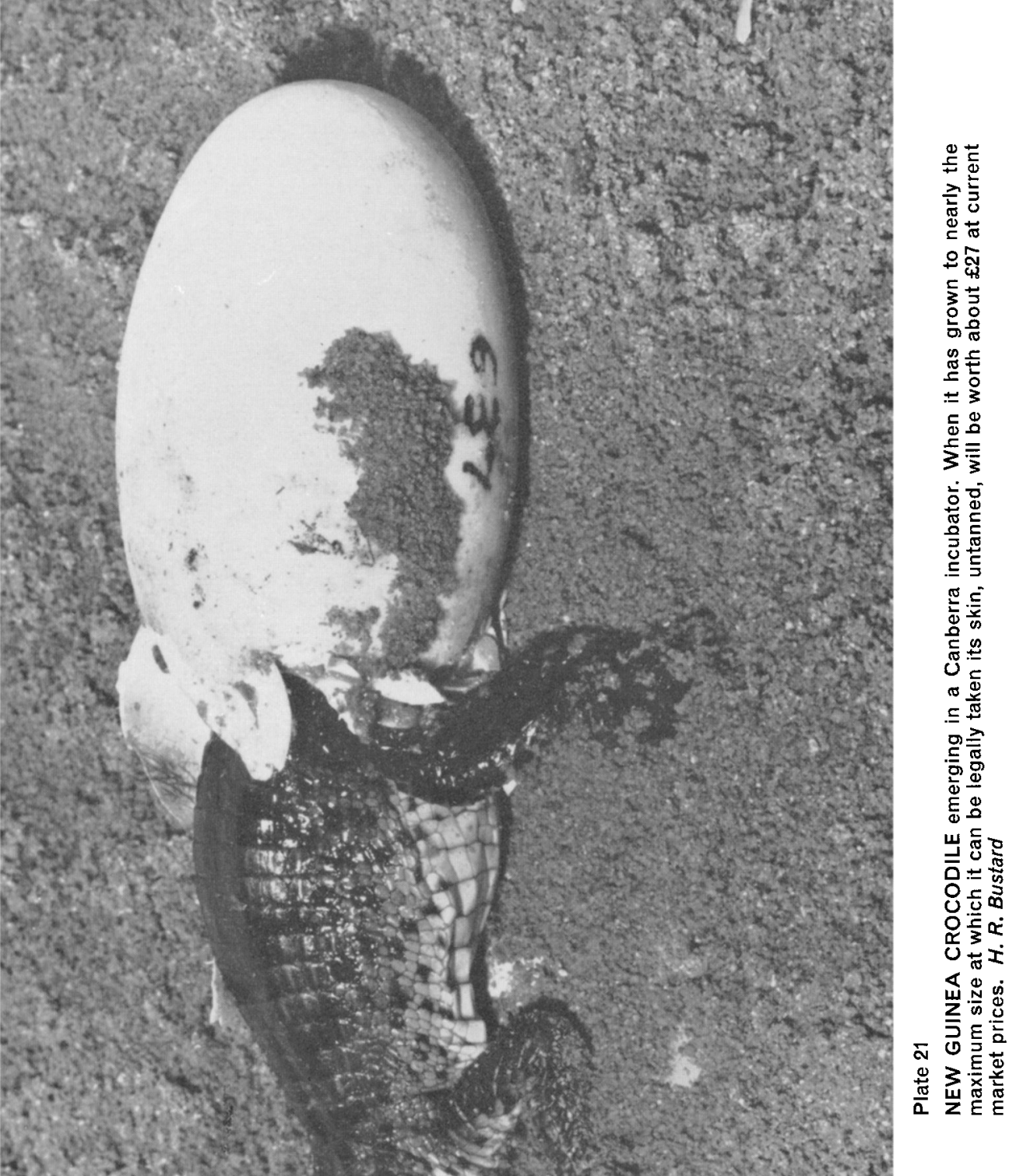

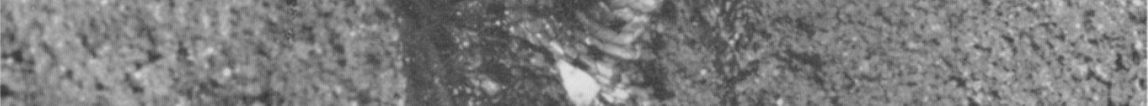

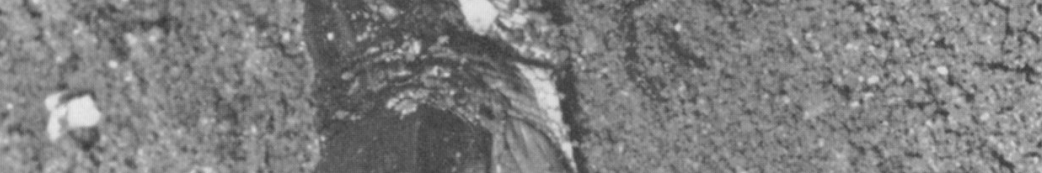

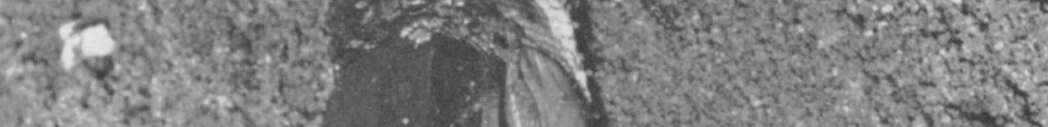
and $3 \times-30$

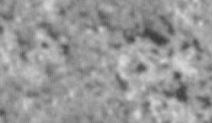

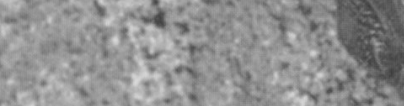
W.

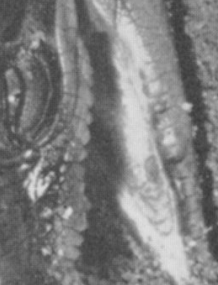

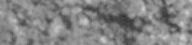

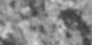

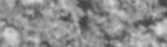
(2) $3 x+2$ 
industry is tied to an equitable and speedy settlement of land ownership problems as they affect crocodiles, and specific legislation is urgently required. The law, as presently interpreted, is that anyone can shoot crocodiles anywhere provided he can get his boat there without traversing native land. It is not sufficient to give the people ownership of crocodiles from enclosed waters only. Many villages possess no totally enclosed waters, and some are seasonally open. Other people live on tributaries or on the main river. Since there is an annual migration of crocodiles from the swamps to the rivers during the dry season, the legislation must also cover the rivers. Since proposals for planned production of the industry will require considerable investment of time and money, the question of ownership of the crocodiles is a real one. Clearly there is no incentive to build up crocodile populations on a local river-swamp complex if anyone can come and shoot them.

2. Size limits: these must be simple to operate. Therefore they must be uniform throughout the Territory; and the same limits must apply to both species, which can be difficult to distinguish at night. The upper limit must protect the remnants of the breeding population; the lower must be designed to safeguard small crocodiles until they reach a profitable size. The lower limit is also a prerequisite for hatchery schemes. The recommended legal limits should result in intensive hunting around the $6-7$ feet mark.

These size limits can be simply policed by making skin examination by agricultural officers mandatory. The check must be made at the time of packing, and the officer responsible must actually seal the crates to prevent the subsequent insertion of illegal-sized skins for transport overseas. It is not suggested that every consignment be examined in full but that stiff penalties together with confiscation of skins be imposed on buyers found in possession of skins outside the legal limits.* As a consequence of introducing size limits, it is essential to ban completely all fishing methods, such as hooking and netting, which do not discriminate the size killed. In most areas it should be simple to prevent hooking by cutting off the supply of hooks. Little netting takes place.

An amnesty period is essential following the introduction of legislation. This must be as short as possible and be used for intensive education. A prolonged amnesty period could result in an all-out slaughter from which the industry would not recover for a generation.

The recommended legal sizes are skins of between $\mathrm{I} 2$ and $20 \mathrm{in}$. belly

\footnotetext{
* The present minor trade in whole small crocodiles as stuffed curios could grow greatly as a result of size limitations, and it must be considered whether there is a place for the curio trade in the future in an industry operated on modern population management lines. Certainly it must be illegal for the valuable saltwater crocodile to be made into curios. Again the practice of keeping small saltwater crocodiles in pens until they reach a commercial skin size could grow rapidly to evade any minimum size restrictions. Since it is easy to catch all the very young crocodiles in an area, this practice could prevent any breeding, so the legislation must be quite explicit-it must prohibit the killing or keeping of crocodiles outside the legal size range.
} 
width. A 12 in. belly cut is equivalent to a 14 in. hornback cut which must, therefore, be the minimum hornback size that can be exported; the maximum hornback size would be 22 in. The recommended belly size limits are represented by a saltwater crocodile of over $5 \frac{1}{2}$ feet and under 8 feet or a freshwater crocodile of over $4 \frac{1}{2}$ feet and under $7 \frac{1}{2}$ feet.

3. Education and better use of man-power: every effort must be made to make readily available information of value to the industry, such as on the skinning and subsequent skin preparation, and the reasons for proposed legislation explained and discussed in detail at the village level. Contact between buyer and shooter must be encouraged, especially on the Sepik, where regulations must result in the disappearance of middle-men.

4. Restocking programme: restocking is urgently required in most areas of the Fly, and is vital for the continuation of the industry on the Sepik. I suggested that the Government run two demonstration 5000-egg hatcheries, one each on the Fly and the Sepik. These hatcheries would receive eggs, hatch the young crocodiles and feed them for one year. After one year the crocodiles would be liberated and the hatchery would take in a freshsupply of eggs. Selected villagers would come to the demonstration hatcheries (as happens under agricultural extension schemes at present) for courses of approximately three months and would then return to set up a hatchery in their own village. Village hatcheries could be operated either by individual owners or by local Government Councils which could employ trained attendants.

Four hundred crocodiles in their first year can be housed in an enclosure measuring 40 feet $\times 40$ feet and will consume on average $20 \mathrm{lb}$. of fish per day throughout the first year. Simple but predatorproof hatcheries like that used for the 50,000 green turtle eggs on the Barrier Reef (see ORYX, May I969, plate I) are envisaged. It is not economic (and certainly not necessary) to keep the crocodiles until they reach an economic skin size. But by keeping them for one year the high loss that occurs among newly hatched crocodiles (which have many enemies) would be avoided.

It is suggested that the people be paid is for each egg brought into their own or Government hatchery, and 9s for each crocodile liberated at one year old. Thus the smallest hatcheries (for I0o crocodiles) would produce an income of $£ 50$ per annum-comparable to an average coffee garden-and there would be a cash return from the first year. The financial return from the hatcheries would, of course, be only a fraction of the return from shooting crocodiles within the legal size limits, but the hatchery re-stocking programme would result in the production of large numbers of crocodiles of this size. Introducing Tilapia into areas where it does not now occur would guarantee an abundant food supply. The initial target would be the liberation of 50,000 baby crocodiles per annum from all hatcheries in the Territory.

The Crocodile Trade Protection Ordinance (1966) in its present form has a number of shortcomings, but it could be made workable with some minor amendments which I have recommended to the 
Administration. An effective Ordinance is an essential first step for the development of the industry. The export value of the industry in terms of untanned skins is currently $£ 470,000$ per annum, which could be built up to about $£ 2,350,000$ over a number of years. In the vast swamplands of the Fly and Sepik the industry's potential is truly tremendous. In addition to providing a very viable local industry in two depressed areas it would contribute substantially to the economy of the Territory. I hope that a local tannery may be set up which would double again the export value.

\section{Results so far}

My report to the Government along the lines I have described has so far achieved two important results: an animal ecologist being directed to the crocodile problem with a substantial budget for pure research on crocodiles, and a field station for work on crocodile biology now being built; and, secondly, new crocodile legislation being enacted incorporating maximum size limits to protect the breeding stock, so that all saltwater crocodiles of breeding size, and the majority of freshwater crocodiles of breeding size, are now totally protected. This action should result in a rapid and continuing increase in the numbers of young crocodiles and so rehabilitate the populations resulting in a gain in long-term productivity. It appears likely that minimum size limits will be imposed in due course to allow the baby crocodiles to reach a more commercial size. Tanning operations have been started on cattle hides, and it is planned to start tanning crocodile skins very soon.

These proposals for Papua-New Guinea could be applied in many areas of the world where once large crocodile populations are now seriously depleted, and unless this approach can be adopted urgently many populations will be extinct in one or two decades. Government legislation is essential together with inspection of skins and heavy penalties for skins above the maximum legal size. To the best of my knowledge Papua-New Guinea is the first country to adopt the biologically valuable concept of maximum size limits although some countries, e.g. West Irian, apply minimum size limits.

\section{Acknowledgments}

I would like to acknowledge the help and discussions I had with very many people in the Territory, and to thank particularly Mr. W. L. Conroy, Director, Department of Agriculture Stock and Fisheries for organising my visit.

\section{References}

BustaRD, H. R. I968 Rapid learning in wild crocodiles (Crocodylus porosus). Herpetologica 24 (2): 173-I75.

CotT, H. B. I96I Scientific results of an enquiry into the ecology and economic status of the Nile Crocodile (Crocodylus niloticus) in Uganda and Northern Rhodesia. Trans. zool. Soc. Lond. 29 (4): 2II-356 